\title{
EXPERIENCIA Y ENSEÑANZA DE OTRAS Literaturas DESDE ARgENTINA. CONJETURAS EN TORNO A UNA BIFRONTALIDAD
}

\author{
Luciana Martínez \\ Universidad Nacional de Rosario \\ Consejo Nacional de Investigaciones Científicas y Técnicas \\ lucianamartinez@gmail.com
}

Resumen: El presente trabajo intenta reflexionar acerca del lugar de la labor docente de Otras Literaturas en Argentina; entendiendo, en primer término, que dicha actividad se encuentra indefectiblemente ligada a fenómenos de recepción, traducción y a tradiciones de lectura que necesariamente marcan la praxis. La elección del concepto "Otras literaturas", en lugar de la tradicional denominación en términos de "literaturas en lenguas extranjeras" (concepto que surgió como resultado de una intensa discusión entre quienes fuimos organizadores del evento en el que este trabajo se presentó: I Encuentro de Estudios Latinoamericanos sobre Otras Literaturas), respondió a la necesidad de pensar lo Otro no sólo en tanto lo ajeno o lo distinto sino también (siguiendo a Lacan) en términos de lo que constituye lo propio. Siguiendo esa hipótesis, se propone una genealogía de docentes marcados por una bifrontalidad, es decir, docentes que se han ocupado tanto de la producción crítica en torno a Otras literaturas como a analizar corpus de la literatura argentina. La labor docente de Otras literaturas en Argentina necesariamente repercute en numerosas ocasiones en la creación de objetos críticos trasversales, cuya formulación se alimenta del cruce de perspectivas. Cabe señalar, por último, que la reflexión a la que este trabajo intenta dar forma apunta a indagar sobre mi propio (doble) posicionamiento como docente en la cátedra de Literatura Europea II e investigadora de CONICET.

Palabras clave: Otras literaturas, Bifrontalidad, Experiencia, Docencia, Investigación.

Abstract: The present work attempts to reflect on the teaching role of Other literatures in Argentina, understanding, in the first place, that this activity is inevitably linked to reception and translation phenomena, as well as to reading traditions that determine the praxis. The choise for the concept "Other literatures", in stead of the traditional denomination "foreign languages literatures" (concept that arouse from an intense debate among those of us who organized the academic event in which this work was presented: I Meeting of Latin American Studies on Other Literatures), respond to 
the need of thinking the Other not only in terms of something foreign or different but also (following Lacan) as something that constitutes the own. Following this hypotesis, the work proposes a genealogy of teaching figures marked by bifrontality, that is, teachers that have focused on the critical production about Other literatures as well as to a corpus of Argentinian literature. The educational work of Other literatures in Argentina often leads to the creation of transversal critical objects, whose formulations feed on crossing perspectives. Finally, it is worth mentioning that the reflection this work tries to shape aims at inquirinng into my own (double) positioning as a teacher of European Literature II and a researcher in the National Scientific and Technical Research Council (CONICET).

Keywords: Other literatures, Bifrontality, Experience, Teaching, Research.

Sobre la experiencia, dicen los que saben, poco puede decirse; menos aún sobre la experiencia de lo Otro. Hablo de la experiencia cuando ya todo pasó, cuando la conmoción que hizo de mí pura destitución en el instante del ahora ha quedado atrás, cuando lo Otro ya no es Otro sino Otro-en-mí, parte de mí, aunque extraña, y lo reconozco como Otro y como propio, por paradójico que suene. Si ese arduo proceso encuentra una elaboración, si puedo hablar después de entonces, se abre un orden simbólico que presenta (como posibilidad sensible) aquello inaprensible que es lo real.

Por eso, hacer docencia es más que un mero ejercicio de la explicación; porque aunque toda explicación supone necesariamente un ordenamiento de ideas, la docencia es además, dominio en el que prima una labor de traducción. Luego de que pasa esa experiencia de encuentro en la lectura 
con un Otro, la docencia es traducción de pensamientos, inferencias, trazados de genealogías de las que nunca (al menos no en el campo de las humanidades) se tienen certezas completas. Entonces la traducción en la docencia es, por un lado, traducción de contenidos, temas, problemas; por el otro, traducción de las propias interpretaciones (y hasta de todo un universo pulsional, si el docente es de temple vehemente) en un sistema más o menos estable, doméstico y domesticable, plausible de ser comprendido. Clase a clase, el docente va construyendo así su obra, completando el devenir de inquietudes y obsesiones desde las que construye ese Otro que es la "Literatura" (porque la Literatura, como diría en más ocasión la profesora Gramuglio, no la hacen los escritores sino los críticos). No obstante, si el docente es "buen" docente, si habilita abrirse la grieta necesaria que invita a la emancipación, entonces admite además que esa obra, que con tanto empeño construye, se "desobre". Ese desobramiento es una no clausura, la apertura de la obra por medio de otras voces, que hacen a su vez hablar del texto mismo otras voces que permanecían, hasta el momento, desoídas. Así, como diría Jean-Luc Nancy (2013) retomando esta categoría de Maurice Blanchot (desoeuvrement), captamos la infinitud en el procedimiento incesante de la obra y la abrimos a la co-creación colectiva, cual sueño romántico de la Poesía Universal Progresiva.

Ahora bien, en el caso que nos atañe, la cuestión puede dificultarse, aún, un poco más. ¿Qué cosa podría complejizar todavía más el enseñar la literatura como otredad, es decir, ser docente de Otras literaturas? Pero antes de todo eso, ¿qué es eso de "Otras literaturas"? Porque hablar de Otras literaturas 
no es meramente una forma elegante de referirse a las literaturas en lenguas extranjeras; aunque, si se lo piensa con detenimiento, tal vez lo extranjero se aplique con precisión a uno mismo cuando se piensa, se enseña o se escribe sobre Otras literaturas. En definitiva, la pregunta es: ¿quién o qué es lo extranjero cuando una o uno se sumerge en Otras literaturas? Cuando unx se aventura sobre el sacro corpus de la Literatura Europea no es más que un desvalido foráneo que cae en harapos una noche de lluvia pidiendo refugio, con sus diccionarios a cuesta. Entrega su singular cabeza litoraleña, tal vez rioplatense, al vértigo de la extranjería y a la tierra siempre incierta de las traducciones previas. La otredad reproducida en un laberinto de espejos, una distancia infranqueable, experiencia en la que nada puedo respecto de lo Otro, apenas mis impresiones que no hacen más que traicionar lo inaprehensible. Porque qué puedo decir yo sobre un inglés victoriano, un ruso, un decadentista francés, ¿cómo es que esa operación de traducción de universos, de Otros mundos, se hace posible? $\mathrm{Y}$, sin embargo, la posibilidad de apertura de lo Otro comienza, muchas veces, en el reconocimiento y reconstrucción del proceso por el que, en el intento histórico de acercamiento hacia lo Otro, lo Otro ha pasado a constituirnos de forma indefectible. Una honda herida para nuestro narcisismo primario, la afirmación suena sin embargo completamente sensata (tal vez pensaría Lacan), si tenemos en cuenta que ya desde el vamos el sujeto nace en el extranjero: nunca se constituye en torno a sí mismo sino en el campo del Otro. 
De este reconocimiento parte la profesora María Teresa Gramuglio (2013) cuando, al analizar las inflexiones de la literatura argentina, afirma en "Literatura argentina y literaturas europeas" que ésta se construye en una indisociable relación respecto de las literaturas europeas, ocupando un rol eminentemente receptor; es decir, traductor. Esa relación quedó sin duda inscripta en el lenguaje (la lengua castellana), al igual que sucede con el portugués en Brasil y con el inglés o el francés en algunos países del Caribe Latinoamericano. Sólo el "espíritu de emancipación" propio del Romanticismo (acaso el costado opuesto e indisociable del anhelo holístico y colectivista de la Poesía Universal Progresiva) que despunta junto con la literatura argentina del siglo XIX hizo posible la apología ilusoria de una libertad absoluta. En ese proceso, me permito agregar, queda no obstante cifrada una conexión con lo Otro (una literatura local cuyo yo está en parte constituido por lo Otro-en-mî) que indudablemente determina las formas históricas de su recepción y transmisión en la escritura crítica y en la práctica docente.

Que toda ontología (colectiva o subjetiva, real y simbólica) se construye en la relación con un Otro es un problema olvidado y hasta incluso negado. ${ }^{1}$ Como si toda afirmación

${ }^{1}$ Le debemos al psicoanálisis (fundamentalmente a Lacan) la puesta en foco sobre la importancia del Otro en la constitución y devenir subjetivos; aspecto que, no obstante, la concepción del sujeto capitalista (siempre entendido en términos de gestor y deudor sólo de sí mismo) parece soslayar. Ahora bien, a la hora de pensar la unidad de la comunidad la cosa cambia radicalmente. Nota Jean-Luc Nancy con acierto que la comunidad propia de la modernidad se basa en una metafísica que ha entendido ambos, el Estado y el sujeto, como inmanencias absolutas (atomismos inconsecuentes, heredados de los axiomas científicos clásicos, agrega Nancy) y que ha erradicado el problema del seren-común, del Mit-dasein heideggeriano. Se trata de un tipo de comunidad que niega al Otro y su insoslayable función tanto en la existencia individual subjetiva como en la 
identitaria fuera hoy tributaria de ese sujeto capitalista, tan de moda, absolutamente autónomo y gestor de sí mismo; lo cierto es que la primacía de los soberbios nacionalismos modernos no ha ayudado a su reconocimiento. Sin apelar a esta imagen, Gramuglio lo comprende perfectamente: mal que les pese, las literaturas nacionales se formaron en una red de relaciones que son en realidad internacionales. Las literaturas nacionales se constituyen en relación con otras literaturas con las que rivalizan, a las que someten o absorben mediante procedimientos de traducción. Sólo el enfoque comparatista, cuya defunción firma tempranamente Rene Wellek en 1958 ("La crisis de la literatura comparada"), habría sabido percibirlo. A principios de siglo XXI, aquellas teorías que reactualizan el comparativismo (principalmente, las de Franco Moretti y Pascale Casanova), aunque teniendo ahora sí en cuenta la asimetría de las literaturas en el espacio global de la "república mundial de las letras", no lograron romper con la hegemonía del estudio y la enseñanza de las literaturas nacionales, que no dejan, en definitiva, de entenderse como atomismos aislados para los que el contacto con lo Otro pareciera anecdótico o accesorio. En el mejor de los casos, como señala con agudeza Gramuglio, esa relación se reduce en las clases a establecer comparaciones implícitas (2013, p. 348).

No obstante, más allá de las orgullosas lucubraciones teóricas a partir de las cuales se ensamblan los diseños curriculares, algo del orden de la nacionalidad y de la lengua misma se trastocan de forma indefectible en la instancia

conformación de cualquier unidad del estar/ser-con; y, por lo tanto, ha conducido a lo largo del siglo XX a la expresión de los totalitarismos (Nancy, 2001) 
siempre íntima de la escritura; hecho que se expresa con transparencia cuando Steiner dice que Borges es el más genial de los escritores angloamericanos (2000, p. 46). Ahí donde los románticos propusieron que entre todos los hombres era el escritor quien encarnaba mejor el Geist (genio) de su Volk o Nación, Steiner encuentra una vuelta de tuerca: la radicalidad de la invención viene siempre de la mano de un lenguaje singularísimo, que crea, incluso sonámbulamente, una propia genealogía; genealogía que se compone no sólo de lo "nacional" sino de lo Otro: lo cosmopolita de la tradición universal es germen seminal de la propia obra. Ahí donde Borges es el más genial de los escritores angloamericanos algo de lo propio y de lo Otro se trastoca, la separación estanca se disloca y pierde sentido ante la eminencia de la singularidad. ${ }^{2}$

Sin pretender acercarnos a la genialidad borgeana, hacer docencia de Otras literaturas en Argentina comparte algo de esa bifrontalidad en la que lo "extranjero" nunca es elemento exclusivo, en el que lo Otro se reconfigura como propio en la construcción de una nueva cadena de genealogías. Incisivamente, de alguna forma, Nicolás Rosa lo señala tempranamente cuando caracteriza de "excesiva" (1981) la obra de Jaime Rest, quien formara los hábitos de gusto e interpretación de los lectores y estudiantes argentinos respecto de las denominadas tradicionalmente "literaturas extrajeras". Años más tarde, Pablo Bardauil (1999), en un texto compilado por el mismo Rosa, dará otro paso y hablará de la producción de Rest en términos de "excentricidad"; momento a partir del

\footnotetext{
${ }^{2}$ La teoría de Steiner retoma sin duda conceptos borgianos desarrollados en ensayos como "El escritor argentino y la tradición" y "Kafka y sus precursores".
} 
cual se establecerá un consenso (Crespi, 2009) en torno a la "inclasificabilidad", "descentramiento", "dispersión", "discontinuidad" de su obra. En efecto, incluso para los estándares curriculares del momento (más flexibles sin duda que los actuales) la versatilidad temática de la obra de Rest lo ubica en un no lugar, en la instancia del paria cuyo pensamiento "excede" los compartimientos en los que siempre se intenta ubicar a la producción académica. Este crítico de "dos literaturas", como lo definió Rosa, cuya obra se encabalga no sólo entre la literatura argentina y la inglesa, sino entre tradiciones críticas vernáculas y "foráneas",3 entre el interés por el ensayo y la crítica académica, entre la "alta literatura" y las manifestaciones de la "cultura de masas" (basta recordar su interés por las letras de tangos y sus estudios sobre cine e historieta), expone la versatilidad de su pensamiento en la temática de sus textos: Cartomancia y poesía (1960), Wesker y su trilogía dramática (1965), Literatura y cultura de masas (1967), La novela tradicional (1967), El teatro moderno (1967), Tres autores probibidos (1968), A Lightning before Death: elaboración de un tema en tres cuentistas (1968), El teatro inglés (1969), Novela, cuento, teatro: apogeo y crisis (1971), El laberinto del universo. Borges y el pensamiento nominalista (1976), Mundos de la imaginación (1978), El cuarto en el recoveco (1982), texto póstumo en el que se compilan sus conferencias sobre Sarmiento, Martínez Estrada, Arlt y Borges.

Esa idea que al parecer apabullaba a la propia Gramuglio, ese fantasma que Judith Podlubne deja registrado en la notable

\footnotetext{
3 Rest pertenece generacionalmente a la revista Contorno pero escribe en Sur. Sus referentes teóricos inmediatos se incluyen en la tradición teórico crítica europea: Bowra, Spencer, Trilling, Praz, Eliot, entre muchos otros (Crespi, 2009).
} 
biografía intelectual que escribe como introducción a Nacionalismo y cosmopolitismo en la literatura argentina (2013), me refiero al hecho de que antes de su publicación María Teresa consideraba la reunión de sus escritos como "un libro imposible", seguramente también le deba algo a esa incómoda bifrontalidad que atraviesa a muchos de los grandes docentes de Otras literaturas: ¿cómo conciliar en un mismo texto reflexiones sobre la revista Sur, sobre Borges, sobre el criollismo, junto con reflexiones teóricas hijas de su experiencia docente en las cátedras de Literatura del Siglo XIX de la UBA y de Literatura Europea II de la UNR? Aquellos que sobrellevábamos con respeto y abnegación durante nuestros primeros años de formación la justa recriminación de la Profesora Gramuglio sobre que nos volcábamos con avidez a escribir sobre corpus vernáculos que poco tenían que ver con los contenidos de la cátedra, no podíamos dejar de preguntarnos por aquél entonces (no podemos aún ahora) cuánto de sus lecturas del realismo francés del siglo XIX y de la novela empirista inglesa del XVIII ampliaron las miras en la producción de aquel maravilloso prólogo a El Imperio Realista; o, a la inversa, cuánto de las lecturas de Mallea, Gálvez, Lugones e incluso Saer modularon sus interpretaciones sobre el realismo y la literatura europea en general. ${ }^{4}$ Lo mismo sin duda cuenta para la producción de Jaime Rest; e incluso podríamos seguir enumerando casos: ¿cuánto de las lecturas de

\footnotetext{
${ }^{4}$ Gramuglio defendía la docencia desde el enfoque comparativista entre las literaturas nacionales europeas; pero, a juzgar por sus reclamos hacia los que éramos docentes en formación en Literatura Europea II, nunca consideró abiertamente legítima (a pesar de la evidente contradicción que se abre ante su propia producción) la bifrontalidad docente, entendida en términos de abocamiento a objetos de estudio tanto europeos como locales.
} 
Alberto Girri hay en las interpretaciones de Sergio Cueto sobre la literatura inglesa?, ¿cuánto de las propias inquietudes líricas de Héctor Piccoli hay en su abordaje de la poesía alemana, a pesar de que es un acérrimo defensor del respeto y la especificidad de las literaturas nacionales? ¿No tiene acaso nuestra propia lectura en general una especie de "filtro borgeano", e incluso un matiz forjado en las discusiones de la revista Sur que se trasmiten subrepticiamente generación tras generación? ¿Enseñamos nosotros, en el litoral o en el Río de la Plata, la misma literatura inglesa, francesa o alemana que se dicta en Inglaterra, Francia, Alemania, o que la que se imparte en Chile, Perú, Colombia, E.E.U.U?

Son varias preguntas que abren un mismo universo de problemas a ordenar. A mi entender, la enseñanza de Otras literaturas está dividida en dos grandes enfoques que de alguna manera se corresponden asimismo con dos perspectivas ideológicamente diferentes sobre la traducción, aspecto nada extraño si se tiene en cuenta que toda docencia (y de forma más notoria la de Otras literaturas) puede considerarse un proceso general de traducción. Por un lado, existe un enfoque que, generalmente vinculado con el dictado en torno a la especificidad de las literaturas nacionales, privilegia como objetivo de máxima la presentación de lo Otro en tanto lo Otro. Meta filosóficamente imposible que, no obstante, sirve de norte, se trata de reproducir las condiciones de producción de ese discurso y mostrarlo en su extrañeza, en su singularidad filológica. Esta perspectiva se hermana con aquel enfoque de la traducción que, lejos de tener como meta la domesticación del texto de base, entiende, a partir de las propuestas de Antoine 
Berman (2004), que toda traducción debe ser una "prueba de lo extranjero", en la que la relación entre lo propio y lo foráneo se muestre en las marcas de un texto que abra lo Otro como completa extrañeza. La traducción ha de presentar lo Otro arrancado, exiliado, conservando toda la fuerza de su singularidad.

Por otro lado, encontramos una segunda perspectiva que contribuye (de forma más o menos consciente) a la elaboración de genealogías productivas de lecturas; ejerce, si se quiere, la "mala lectura o mala traducción" borgeana, en el sentido de desestabilización creativa de un texto que no se considera nunca como definitivo. No es, en este caso al menos, que esta "mala lectura" desatienda la debida contextualización del texto (nadie podría negar el rigor de los intelectuales "bifrontales" que hemos nombrado), sino que su metodología, en donde prima la sincronicidad y la multiplicidad referencial en la elaboración de genealogías propias de lectura, en lugar de la cronología y la causalidad, naturalmente crea un lugar propio para cualquier texto, una ubicación en la que cualquier contenido se resignifica, en el que ese Otro constituye lo propio y lo propio se resemantiza en relación con lo Otro. Más o menos explícitamente (creo que menos que más, para ser precisa), en esa genealogía creativa ya no se piensa lo Otro como tal sino lo Otro-en-mí, y lo propio-en-lo-Otro. Se trata de una lectura-traducción-docencia que retoma el potencial creador que tuvo para Latinoamérica la traducción desde el siglo XIX como forma privilegiada de producción en la periferia (Waisman, 2005). 
Asumir dicha metodología es sin duda algo complejo, más aún en un contexto neoliberalista que impone mandatos de rigurosa especificidad (o sea, de división del trabajo intelectual) bajo la forma de la "excelencia académica", la cual se alimenta además de la legitimidad de la que siempre gozó la enseñanza ordenada en torno a los nacionalismos culturales.

Pero, además, proponer tal enfoque parecería volver sobre el viejo concepto goethiano de Weltliteratur, aquella perspectiva cosmopolita que se basó inicialmente en la creencia de Goethe en las interrelaciones y armonía subyacentes en toda materia, que formó parte de su obsesión protorromántica por la búsqueda de unidades primigenias. Para Goethe, leer y escribir sobre lenguas y tradiciones literarias disímiles, favorecía el "libre comercio" intelectual y espiritual, porque, además, quien no conocía lenguas extranjeras "no sabía nada de la suya propia" (Steiner, 1997, p. 141). De este modo es evidente que lo Otro juega un papel destacado en el concepto goethiano de "Literatura mundial". Empero, como advirtieron luego los estudios postcoloniales, convendría a las naciones periféricas tener cuidado respecto de ese espíritu cosmopolita y su proclama de paz y fraternidad, estar atentos al oscuro revés que esconden las falsas simetrías de toda empresa de colonización cultural. Es decir, en la Weltliteratur el flujo de intercambio por el que lo Otro se vuelve constitutivo de lo propio, lejos de tomar la dinámica de un idílico equilibrio, se ve regulado por fuertes jerarquías.

¿Qué sentido tiene entonces legitimar una bifrontalidad que, lateral pero indefectiblemente, nos acerque a pensar los problemas de la literatura en un contexto de miras amplias? El 
sentido se encuentra sin duda en el gesto de agenciamiento, ya que, pensada desde Latinoamérica, desde Argentina, la literatura europea (o mundial en un sentido más amplio) puede tener otras connotaciones, en los términos a partir de los que se pensó desde antaño la traducción, es decir, como apropiación productiva desde la periferia. Mirar (siempre con cautela) lo Otro en el contexto de lo propio, confrontarlo, medirlo de igual a igual, responde a un universo ideológico que equipara producciones culturales en la construcción de genealogías. Es, al mismo tiempo, un gesto de resistencia a la especificidad que nos impone el neoliberalismo en épocas de la "excelencia" académica. La bifrontalidad se complejiza además con la proposición de una dialéctica: dar lugar a la enseñanza de lo Otro en su singularidad, pero volver ese ejercicio productivo en la creación de objetos críticos transversales a partir de los cuales se enriquezcan las perspectivas de lo propio y de lo Otro. Dar lugar a objetos que se habilitan por la apertura y exploración de ese campo de interferencia que se genera en la experiencia de lo Otro desde el Cono Sur americano. Asumir que la construcción y trasmisión de lo Otro se realiza siempre desde lo Otro-en-mí, instancia que supone apropiarse del lugar y la riqueza de un sujeto fracturado, a partir del cual se dictan Otras literaturas desde Latinoamérica. ${ }^{5}$

\footnotetext{
${ }^{5}$ La producción de mi propia tesis doctoral ("Ciencia y literatura en el Río de la Plata. Modulaciones de una epistemología alterna en las obras de Mario Levrero y Marcelo Cohen") es, en este sentido, un resultado de la mentada bifrontalidad. Digo esto porque, si bien la misma estudia las relaciones entre literatura y ciencia en un corpus rioplatense, la producción del estado de la cuestión del problema está indisociable y pertinentemente ligado a mis conocimientos, gracias a mi rol docente en Literatura Europea II, sobre las relaciones entre literatura y empirismo durante el siglo XVIII y XIX, como así también sobre las postulaciones de la "ciencia romántica". En este sentido, entiendo que la
} 


\section{Referencias Bibliográficas}

Bardauil, P. (1999). "El excéntrico Jaime Rest". Rosa, N. (comp.): Políticas de la crítica. Historia de la crítica literaria en la Argentina. Buenos Aires: Biblos. pp. 183-215.

Berman, A. (2004). "Translation and the trial of foreign". Venuti, L.: The Translation Studies Reader. New York: Routledge. pp. 284-296.

Borges, J. L. (1992). "El escritor argentino y la tradición". Discusión. Obras Completas (volumen I). Buenos Aires: Círculo de Lectores. pp. 296-303.

---------- (1992). "Kafka y sus precursores". Otras Inquisiciones, Obras Completas (volumen II). Buenos Aires: Círculo de Lectores. pp. 303-305.

Casanova, P. (2001). La República mundial de las letras. Barcelona: Anagrama.

Crespi, M. (2009). “Jaime Rest: ficción e imaginación crítica”. Boletín de Estética, CIF (Centro de Investigaciones Filosóficas, Programa de Estudios en Filosofía del Arte), año V, número 8. pp. 41-69.

Damrosch, D. (2008). "Toward a History of World Literature". New Literary History (The Johns Hopkins University Press), Vol. 39, No. 3, Literary History in the Global Age (Summer). pp. 481-495.

Even-Zohar, I. (1994). "La función de la literatura en la creación de las naciones de Europa". Villanueva, D. (ed.): Avances en

intersección de objetos y corpus de investigación y docencia dieron lugar a la conformación de un objeto singular en el que, por un lado, el problema de la ficcionalización de la ciencia en el corpus rioplatense puede ser pensado con amplitud gracias la construcción de un estado de la cuestión formulado a partir de un conocimiento privilegiado de la literatura europea; por otro lado, la lectura desde la complejidad del corpus rioplatense, eslabón avanzado del problema propuesto, permite reconfigurar la genealogía de la relación literatura-ciencia de una forma particular, iluminar ángulos inusitados y pensar vinculaciones con otras manifestaciones literarias contemporáneas desde otra óptica. 
Teoría de la literatura: Estética de la Recepción, Pragmática, Teoría Empírica y Teoría de los Polisistemas. Santiago de Compostela: Universidade de Santiago de Compostela. pp. 357-377.

Gramuglio, M. T. (2013). Nacionalismo y Cosmopolitismo en la Literatura Argentina. Rosario: Editorial Municipal de Rosario.

Jameson, F. (1987). "World Literature in an Age of Multinational Capitalism". Ed. Koelb, C. \& V. Lokke: The Current in Criticism: Essays on the Present and Future of Literary Theory. West Lafayette: Purdue University Press. pp. 139-158.

Lacan, J. (2014). "El sueño de la inyección de Irma", "El sueño de la inyección de Irma (fin)" y "Introducción del gran Otro". El Seminario 2. El yo en la teoría de Freud y en la técnica psicoanalítica. Buenos Aires: Paidós. pp. 223-262, 353-370.

Moretti, F. (2007). La literatura vista de lejos. Barcelona: Marbot.

Nancy, J-L. (2013). "De la obra y de las obras". La partición de las artes. Valencia: Pre-Textos. pp. 71-83.

---------- (2001). La comunidad desobrada. Madrid: Arena.

Rosa, N. (prólogo y selección) (1981). La crítica literaria contemporánea (Colección Capítulo, $\mathrm{n}^{\circ}$ 113). Buenos Aires: Centro Editor de América Latina.

Steiner, G. (1997). “¿Qué es la literatura comparada?”. Pasión intacta. Madrid: Siruela. pp. 135-162.

(2000). Extraterritorial. Ensayos sobre literatura y la revolución de lenguaje. Buenos Aires: Adriana Hidalgo.

Torre, M. E. (2000). “Jaime Rest, un cuarto propio”. Boletín/8 del Centro de Estudios de Teoría y Crítica Literaria, pp. 125144. 
Waisman, S. (2005). Borges y la traducción. Buenos Aires: Adriana Hidalgo.

Wellek, R. (1963). "The Crisis of Comparative Literature.". Ed. S. G. Nichols, Jr.: Concepts of Criticism. New Haven: Yale UP. pp. 282-295. 